\title{
A concepção de corpo e sua interface entre gênero e sexualidade nos PCNs e na BNCC
}

\author{
The conception of the body and its interface between gender \\ and sexuality in PCNs and BNCC
}

\section{La concepción del cuerpo y su interfaz entre género y sexualidad en PCNs y BNCC}

\author{
Jeizi Loici Back
}

Universidade Estadual do Paraná (Unioeste), Cascavel/PR - Brasil

Francis Mary Guimarães Nogueira

Universidade Estadual do Paraná (Unioeste), Cascavel/PR - Brasil

\section{Resumo}

Esta pesquisa examina a concepção de corpo e sua interface entre gênero e sexualidade, expressa nas políticas educacionais dos anos de 1990, nos Parâmetros Curriculares Nacionais (PCNs) e na Base Nacional Comum Curricular (BNCC) vigente. A metodologia se restringiu à pesquisa documental e bibliográfica e apontou que o corpo, como construção sócio-histórica, vem sendo normatizado de acordo com as necessidades de cada momento político no Brasil. Nessa perspectiva, a escola atua como importante instituição que opera para a normatização, refletida na implantação dos PCNs e da BNCC.

Palavras-chave: PCNs, BNCC, Normatização dos corpos, Gênero e sexualidade

\begin{abstract}
This research examines the conception of body and its interface between gender and sexuality, expressed in the educational policies of the 1990s, in the National Curriculum Parameters (PCNs) and in the current National Common Curricular Base (BNCC). This is a documentary and bibliographic research, which pointed out that the body as a socio-historical construction has been standardized according to the needs of each political moment in Brazil. In this perspective, the School acts as an important institution, which operates for standardization, reflecting on the implementation of PCNs and BNCC.
\end{abstract}

Keywords: PCNs, BNCC, Body standardization, Gender and sexuality

\section{Resumen}

Esta investigación examina la concepción de cuerpo y su interfaz entre género y sexualidad, expresada en las políticas educativas de la década de 1990, en los Parámetros Curriculares Nacionales (PCNs) y en la Base Nacional Curricular Común (BNCC) en vigencia. La metodología se restringió a la investigación documental y bibliográfica y señaló que el cuerpo, como construcción sociohistórica, se ha estandarizado de acuerdo con las necesidades de cada momento político en Brasil. En esta perspectiva, la escuela actúa como una importante institución que opera para la homogeneización, reflejada en la implantación de los PCNs y de la BNCC.

Palabras clave: PCNs, BNCC, Estandarización de los cuerpos, Género y sexualidad 


\section{Introdução}

O presente artigo é parte do resultado de pesquisa realizada no Programa de Pós-Graduação stricto sensu, nível de mestrado, com área de concentração em Sociedade, Estado e Educação, da Universidade Estadual do Oeste do Paraná, campus de Cascavel. Intitulada Normatização dos corpos pela escola: uma análise da BNCC (Base Nacional Comum Curricular), objetivou analisar como a instituição escola, com a implantação da política educacional da BNCC, contribui para a normatização dos corpos, a partir da interface entre corpo, gênero e sexualidade.

Entretanto, este artigo tem como fim analisar qual a concepção de corpo e sua interface entre gênero e sexualidade presente nos PCNs (Parâmetros Curriculares Nacionais) e na BNCC. Assim, se faz importante informar que a análise da BNCC ficou restrita às etapas da educação infantil e do ensino fundamental.

As ferramentas escolhidas para a produção de dados foram a pesquisa exploratória, em fontes primárias, no caso dos PCNS e da BNCC, e em fontes secundárias, com a leitura de diversos autores e autoras a fim de realizar as reflexões e análises sobre o tema.

Escolheram-se os PCNs, por se tratar de documento orientador da escola e das práticas pedagógicas. E embora tenha sido aprovado em um período de ascensão do neoliberalismo, ele abre caminho, por meio dos temas transversais, para discutir questões referentes a gênero e sexualidade no cotidiano escolar. Ou seja, mesmo com a penetração do projeto neoliberal caracterizado pela privatização do Estado, não houve um ataque às discussões emergentes daquele período relacionadas a gênero, diversidade sexual e educação sexual na Escola e na sociedade como um todo.

Porém, depois de um período de neodesenvolvimentismo no Brasil e com a retomada dos valores neoliberais, a BNCC se apresenta como documento mandatório da organização e práticas escolares e traz para dentro da escola a negação dos valores de igualdade de gênero, da diversidade sexual e da educação sexual. Assim, reafirma os padrões heteronormativos, presentes no discurso de ódio e negacionismo da ciência, que se propagou por toda a sociedade, vinculados ao fundamentalismo religioso.

Dessa forma, aponta-se, neste artigo, para as evidências encontradas ao se responder à questão: qual a concepção de corpo presente nos PCNs e na BNCC? 
A Escola se configura como espaço de normatização dos corpos e como espaço de materialização das políticas supracitadas; além disso, é instrumento fundamental para a manutenção do establishment da sociedade brasileira. $\mathrm{Na}$ investigação, afirma-se, a partir de literaturas consagradas, que o corpo é a materialidade da vida humana, que os seres humanos só existem porque possuem corpos.

Outro pressuposto necessário para que o(a) leitor(a) compreenda o caminho percorrido por este trabalho, é o de que o corpo não é apenas um receptáculo da existência humana. De acordo com Turner (2014, p.66), o corpo "é produto de relações de poder e política. O corpo como objeto de poder é produzido a fim de ser controlado, identificado e reproduzido".

Além disso, faz-se necessário deixar claro que os corpos são normatizados de acordo com as necessidades das classes dominantes de cada período histórico. E desde o surgimento da propriedade privada, do Estado e das classes sociais, os corpos masculinos e femininos são normatizados de maneiras distintas e desiguais, pois "nenhuma sociedade deixa a reprodução social ao livre arbítrio dos indivíduos" (TURNER, 2014 p. 71). Ou seja, os corpos são normatizados para atender às exigências de grupos hegemônicos de determinado período histórico.

Dessa forma, historicamente, o sistema capitalista necessitou normatizar os corpos dos trabalhadores(as) para atender às suas demandas, pois, de acordo com Marx (1983, p.176), "o trabalhador labuta além dos limites do trabalho necessário, embora lhe custe trabalho, dispêndio de força de trabalho, não cria para ele nenhum valor. Ele gera a mais-valia, que sorri ao capitalista com todo o encanto de uma criação do nada".

Esse tempo de trabalho, realizado pelo(a) proletário(a) e que não lhe "gera valor", ou seja, pelo qual não recebe a mais, é apropriado pelo capitalista. Isso se torna possível devido à normatização do sistema capitalista sobre seu corpo, que o faz trabalhar por longas jornadas, recebendo apenas uma parte de seu trabalho, e não a sua totalidade.

Portanto, compreende-se que a normatização dos corpos diz respeito, segundo Zanatta (2017), a um conjunto de normas, regras e crenças que determinam comportamentos, ou seja, ditam sobre o que é ser homem e mulher na sociedade. 
Segundo Butler (2018, p.195): "as normas regulatórias do sexo trabalham de uma forma performativa para construir a materialidade dos corpos e, [...] para materializar a diferença sexual a serviço da consolidação do imperativo heterossexual".

Assim, pode-se afirmar que nossos corpos são imersos em normas, crenças, regras, leis, por meio de diversas instituições como a família, religião, Estado e consequentemente a Escola, que nos ensinam como devemos ser, parecer, agir e até por quem sentir atrações. Também fica nítido na citação de Butler (2018), que essas normas se pautam no "imperativo heterossexual", patriarcal, misógino e lgbtfóbico.

Ressalte-se, ainda que, aqui, parte-se da compreensão de que "o gênero é um elemento constitutivo de relações sociais baseadas nas diferenças percebidas entre os sexos, e o gênero é uma forma primeira de significar as relações de poder" (SCOTT, 1989, p. 21, grifos da autora), nas quais o sexo masculino se sobrepõe ao feminino.

Outro conceito que se precisa apresentar é o referente à identidade de gênero, que "define o grau em que cada indivíduo se identifica com o masculino e com o feminino ou com ambos" (BRÊTAS, 2011, p. 88). Portanto, a forma de se identificar com tais papéis pode destoar do sexo biológico, e, com isso, o indivíduo passa a se apresentar socialmente de acordo com sua identificação subjetiva.

E por fim, faz-se necessário deixar claro que a "orientação do desejo sexual diz respeito ao desejo erótico, é o sentimento de atração que temos por uma ou várias pessoas tanto no âmbito afetivo como sexual" (BRÊTAS, 2011, p. 90) e que pode ser direcionado ao mesmo sexo, ao sexo oposto, a ambos ou a nenhum. Portanto, não se configura como uma escolha ou "opção", e, sim, como algo inerente à existência humana.

Desse modo, essas foram as concepções que nortearam a discussão, relativas à concepção de corpo e sua interface entre gênero e sexualidade, nos PCNs e na BNCC.

\section{A Escola como espaço de normatização de corpos}

Diante das questões apresentadas anteriormente, faz-se necessário pensar qual é o papel da instituição escolar na normatização dos corpos e para a manutenção das relações de gênero necessárias à sociedade capitalista. 
Como recorte histórico, pensaremos o processo escolar a partir da revolução industrial, pois é o período em que o capitalismo passa a ser o modo de produção dominante e em que se reconfiguram a forma de trabalho e a organização da vida cotidiana, ou seja, "a revolução industrial muda também, as condições e as exigências da formação humana" (MANACORDA, 2010, p. 327).

[...] a proliferação da indústria iria exigir um novo tipo de trabalhador. Já não bastaria que fosse piedoso e resignado, embora isto continuasse sendo conveniente e necessário. A partir de agora, deveria aceitar trabalhar para outro e fazê-lo nas condições que este outro lhe impusesse. Se os meios para dobrar os adultos iam ser a fome, o internamento ou a força, a infância (os adultos das gerações seguintes) oferecia a vantagem de poder ser modelada desde o princípio de acordo com as necessidades da nova ordem capitalista e industrial, com as novas relações de produção e os novos processos de trabalho (ENGUITA, 1989, p.113).

Portanto, a escola de massa nasce da necessidade de se qualificar e normatizar a forma de trabalho para a indústria e, embora haja dicotomia entre a educação para a elite e a educação para a classe trabalhadora, a escola de massa se configura como uma necessidade da burguesia.

Certamente, conforme o capitalismo se modifica, a escola também sofre modificações, principalmente, no que diz respeito às questões pedagógicas e metodológicas. É importante destacar que, assim como na sociedade, a escola também se configura como espaço de disputa de classes e de contradições, mesmo que não deixe de cumprir com o papel de formar e qualificar a força de trabalho necessária para o sistema capitalista. Portanto, é uma instituição normatizadora de corpos.

Segundo Louro (2018, p. 25-26):

Um corpo escolarizado é capaz de ficar sentado por muitas horas e tem, provavelmente, habilidade para expressar gestos ou comportamentos indicativos de interesse e de atenção, mesmo que falsos. Um corpo disciplinado pela escola é treinado no silêncio e num determinado modelo de fala; concebe e usa o tempo e o espaço de uma forma particular. Mãos, olhos e ouvidos estão adestrados para tarefas intelectuais, mas possivelmente desatentos ou desajeitados para outras tantas.

Dessa forma, quanto às questões que envolvem gênero e sexualidade, de acordo com Louro (2018), a escola precisa incentivar a "sexualidade normal", ou seja, a heterossexualidade, ao mesmo tempo em que precisa contê-la. Assim, cria-se a ideia de que a escola não é local para discutir questões referentes a gênero e sexualidade, a não ser em um caráter higienista e mecânico do corpo. 
Todavia, conforme já mencionado, a escola é um espaço de disputa e contradições, e educar é um ato político. Por isso, é fundamental discutir e incluir nos currículos escolares temas voltados à educação sexual, a fim de se superarem os ideais higienistas e mecanicistas ligados à sexualidade humana. Furlani (2009, p. 45) mostra que:

[...] educar não é um ato neutro; que há uma íntima relação entre o que pensamos e nossa prática pedagógica; que toda prática docente é amparada por uma teorização (mesmo que não tenhamos consciência dela); que a formação docente (os cursos de formação) e a educação continuada deveriam refletir esses pressupostos teóricos e práticos; que o ato pedagógico é permeado de decisões, escolhas e, portanto, por disputas de saberes e significados... Tudo isso torna a educação uma ação, permanentemente, política.

Nesse sentido, deixar a educação sexual apenas como responsabilidade da família é compactuar com o alto índice de violência sexual contra crianças, pois, muitas vezes, a escola é o único espaço em que as crianças aprendem a prevenir e a denunciar abusos. Conforme Vilela (2019), mais de 70\% dos casos de violência contra crianças e adolescentes ocorrem dentro de casa.

Assim, a Escola se configura, ao longo da história, como importante "aparelho ideológico do Estado"1 e como instrumento de normatização de corpos, a fim de atender às demandas da sociedade capitalista. Mesmo que submersa em contradições e disputas, ela cumpre esse importante papel. Porém, não há que se olhar para esse cenário de maneira derrotista, mas, sim, a partir de tal materialidade, há que se pensar como é possível construir novas relações de gênero e de corpos emancipados.

\section{A concepção de corpo e sua interface entre gênero e sexualidade presente nos PCNs}

Apesar de a Constituição de 1988 representar um grande avanço na construção de políticas públicas, na década de 1990 - durante os mandatos do presidente Fernando Henrique Cardoso -, não se verifica uma correspondente melhoria de vida. O que se vê são as políticas neoliberais sequestrarem o Estado e ocasionarem altas

\footnotetext{
${ }^{1}$ Segundo Althusser (1980, p.47), os Aparelhos Ideológicos de Estado funcionam de um modo massivamente prevalente pela ideologia, embora funcionando secundariamente pela repressão, mesmo que, no limite, mas apenas no limite, esta seja bastante atenuada, dissimulada ou até simbólica. (Não há aparelho puramente ideológico).
}

Revista Educação Online, Rio de Janeiro, n. 36, jan-abr 2021, p. 70-89 
taxas de desemprego e consequente diminuição da renda da população já empobrecida.

Em relação às políticas educacionais do período, temos o seguinte cenário: a aprovação da Lei de Diretrizes e Bases da Educação (LDB), em 1996, e dos Parâmetros Curriculares Nacionais (PCNs), em1997.

Os PCNs estão organizados em dez volumes ${ }^{2}$ e se apresentam como uma proposta flexível, que respeita as diferenças culturais de todo o país, conforme descrito no documento:

Não configuram, portanto, um modelo curricular homogêneo e impositivo, que se sobreporia à competência político-executiva dos Estados e Municípios, à diversidade sociocultural das diferentes regiões do País ou à autonomia de professores e equipes pedagógicas. (BRASIL, 1997, p.13)

É importante observar que um dos volumes do documento é destinado a temas transversais ${ }^{3}$; a orientação sexual é um dos temas abordados que, em tese, deveriam apresentar-se como norteadores das áreas do conhecimento.

Entretanto, o termo "orientação sexual" no lugar de "educação sexual"4 ocasionou certa confusão e estranheza, pois, ao usar "tal denominação, o documento retirava do conceito já estabelecido de orientação sexual - que diz respeito às práticas sexuais homo, bi e heteroeróticas, uma nomenclatura que fora construída nas lutas sociais recentes" (CÉSAR, 2009, p. 53).

Além disso, reforça o senso comum de que o desejo sexual dos indivíduos é uma opção, pois, se a escola deveria ensinar a orientação sexual "logicamente, no imaginário da maioria, a homossexualidade só poderia estar ligada a uma opção sexual, já que a escola 'orientava' a sexualidade das alunas e alunos" (SANTOS; ARAÚJO, 2009, p. 18).

\footnotetext{
2 Organização dos volumes dos PCNs: um, referente à introdução; seis, destinados às áreas de conhecimento: língua portuguesa, matemática, ciências naturais, história, geografia, arte e educação física; e três que tratam dos temas transversais: ética, pluralidade cultural, orientação sexual, meio ambiente e saúde.

${ }^{3}$ Quanto ao desenvolvimento dos temas transversais, o documento afirma que "as questões sociais se integram na própria concepção teórica das áreas e de seus componentes curriculares" (BRASIL, 1997, p 41).

${ }^{4}$ Em 1995, foi realizado em Florianópolis e organizado pelo MEC um Encontro de Educadores(as) de Universidades da Região Sul, para discussão dos documentos dos PCNs. Ao seu final, em Assembleia Geral, elaborou-se uma moção que expressava o desejo das(os) participantes pelo uso (e manutenção) da expressão educação sexual e não da orientação sexual nos documentos do MEC" (FURLANI, 2009, p. 40, grifos do autor).
}

Revista Educação Online, Rio de Janeiro, n. 36, jan-abr 2021, p. 70-89 
É possível perceber um avanço na compreensão da sexualidade humana, no documento, quando se afirma que "se, por um lado, sexo é expressão biológica que define um conjunto de características anatômicas e funcionais (genitais e extragenitais), a sexualidade é, de forma bem mais ampla, expressão cultural" (BRASIL, 1997, p. 81). E na sequência mostra que "cada sociedade cria conjuntos de regras que constituem parâmetros fundamentais para o comportamento sexual de cada indivíduo" (BRASIL, 1997, p. 81).

Porém, o documento não faz referência às questões raciais e de classe que englobam a sexualidade, bem como, ao separar gênero das sexualidades, configurase como uma problemática, pois as questões de submissão das mulheres aos homens também estão presentes nas relações sexuais e afetivas. Portanto, "as questões relativas a gênero deveriam perpassar toda a discussão sobre sexualidade, corpo e prevenção, sem que sua abordagem ficasse circunscrita a um bloco específico" (VIANNA; UNBEHAUM, 2004, p. 42).

Ainda sobre as questões de gênero, apresenta que "Enquanto o sexo diz respeito ao atributo anatômico, no conceito de gênero toma-se o desenvolvimento das noções de 'masculino' e 'feminino' como construção social” (BRASIL, 1997, p. 99100).

Identifica-se, nessa afirmativa, uma relativização das questões que envolvem os processos históricos de dominação masculina sobre o feminino. Também se ignora a necessidade dessa dominação para a manutenção da sociedade de classes e, com isso, as questões políticas são colocadas de lado. Dessa forma, demonstra a posição política do documento de manutenção da sociedade capitalista e patriarcal.

Outro fator importante nos PCNs é sua concepção de corpo, ao compreendêlo para além das determinações biológicas, perceptível na seguinte afirmação: "a abordagem sobre corpo deve ir além das informações sobre sua anatomia e funcionamento, pois os órgãos não existiriam fora de um corpo que pulsa e sente" (BRASIL, 1997, p. 96). Além disso, apresenta a necessidade de se questionarem os padrões de beleza estabelecidos pela mídia e a importância de se cuidar do corpo para o bom desenvolvimento da sexualidade.

Quanto às relações de gênero que perpassam a constituição dos corpos, os PCNs ficam na superficialidade, ao afirmarem que "devem [...] ser abordadas as 
transformações do corpo que ocorrem na puberdade, os mecanismos da concepção, gravidez e parto, assim como a existência de diferentes métodos contraceptivos e sua ação no corpo do homem e da mulher" (BRASIL, 1997, p. 97). Ao se falar sobre gravidez, é fundamental que se considere a carga social existente sobre as mulheres - as mães e as que não pretendem ser - e os estereótipos das mães-solo, em contraposição à responsabilidade versus o abandono paterno, e a prevenção da gravidez como responsabilidade de homens e mulheres. Os métodos contraceptivos mais comuns - os hormonais - afetam diretamente o corpo feminino; logo, essa discussão deveria aparecer como central, ao se discutir a ação dos métodos contraceptivos "no corpo do homem e da mulher" (BRASIL, 1997, p. 97).

Nesse sentido, as autoras Vianna e Unbehaum (2004, p. 43) afirmam que seria necessário orientar os(as) professores(as) a considerarem os padrões de conduta estabelecidos historicamente. Citam como exemplo os que "impedem a mulher de exigir de seu parceiro o uso do preservativo, ou ainda a levam a se autopunir (psiquicamente) por tomar anticoncepcional" (VIANNA; UNBEHAUM, 2004, p.43).

Por fim, outro aspecto questionável quanto à forma de tratar a sexualidade é o bloco destinado à prevenção das doenças sexualmente transmissíveis, em especial, a Aids. Não se trata de negar a importância dessa questão; tal preocupação é legítima e é necessário vinculá-la às questões da sexualidade e de gênero. Porém, "ao associar a sexualidade com a saúde, favorece-se, mesmo não desejando, uma abordagem restrita à prevenção e à doença" (VIANNA; UNBEHAUM, 2004, p.43).

Apesar de uma série de problemáticas, percebe-se que os PCNs cumprem papel importante quanto às discussões acerca da educação sexual no Brasil.

\section{A concepção de corpo e sua interface entre gênero e sexualidade presente na BNCC}

Entre os PCNs e a aprovação da BNCC, passaram-se mais de 20 anos. Nesse período, o Brasil vivencia uma política de conciliação de classes, durante os governos Lula e Dilma. Portanto, vê-se grande parte da população sair da linha de extrema pobreza e o Brasil sair do mapa da fome. Ao mesmo tempo, o capital financeiro consolida-se como a fração de classe hegemônica no poder, juntamente com os produtores de commodities. Esse fato pode ser observado pelo aumento dos lucros, 
uma vez que a "participação do lucro líquido da indústria de commodities intensivos em capital (IC) foi fortemente influenciado pelos desempenhos da Vale e Petrobrás, já que os dois grupos foram responsáveis por mais de $50 \%$ dos lucros líquidos da IC" (TEIXEIRA; PINTO, 2012, p. 929).

Esse modo de governo de coalizão de classes, entretanto, não dura: mesmo que Dilma Rousseff tenha sido reeleita democraticamente nas eleições de 2014, não consegue concluir seu mandato, pois a "Nova direita" (CASIMIRO, 2018) "associada a outras vertentes políticas, organizou com apoio jurídico, parlamentar e midiático o golpe de 2016, por dentro da democracia liberal" (FREITAS, 2018, p. 15).

Além do mais, essa ilegalidade possibilita uma crescente prática de políticas fascistas, o avanço do capital empresarial e financeiro e o assédio do fundamentalismo religioso sobre o Estado. Tal processo tem, ainda, reflexos sobre as políticas públicas e, consequentemente, sobre o sistema de educação.

É justamente nessa conjuntura, que é aprovada a terceira versão da BNCC, em 20 de dezembro de 2017. Porém, a etapa do ensino médio só é incluída em abril de 2018, com destaque para a participação de vários agentes privados na elaboração do documento. De acordo com Macedo (2014), entre os agentes privados que conduziram o debate, encontram-se as seguinte instituições financeiras e empresas: "Itaú [Unibanco], Bradesco, Santander, Gerdau, Natura, Volkswagen, entre outras além de Fundação Victor Civita, Fundação Roberto Marinho, Fundação Lemann, CENPEC, Todos pela Educação, Amigos da Escola" (MACEDO, 2014, p. 1540).

Chama atenção o detalhe de que, na terceira versão, não se menciona a participação das Universidades. Segundo D’Avila (2018, p. 70), esse "fato que evidencia o caráter antidemocrático e pouco transparente desse processo".

Sobre a terceira e última versão da BNCC, sancionada pelo então ministro da Educação, Mendonça Filho, em 2017, outra questão importante a se destacar é a de se suprimir, de vários trechos do texto, a palavra gênero e diversidade sexual. $O$ ministro, em seu pronunciamento em rede nacional de TV, faz a seguinte afirmação: "[...] a Base está sendo entregue aos brasileiros sem ideologia de gênero" (BRASIL, 2017). Com isso, atendem-se aos interesses de grupos ligados ao fundamentalismo religioso, que passam a ter poder sobre o Estado e usam o biologismo para justificar 
a opressão de gênero e, com isso, reafirmar a heteronormatividade. De acordo com Reis e Eggert (2017, p.20),

Criou-se uma falácia apelidada de "ideologia de gênero", que induziria à destruição da família "tradicional", à legalização da pedofilia, ao fim da "ordem natural" e das relações entre os gêneros, e que nega a existência da discriminação e violência contra mulheres e pessoas LGBT comprovadas com dados oficiais e estudos científicos. Utilizou-se de desonestidade intelectual, formulando argumentos sem fundamentos científicos e replicando-os nas mídias sociais para serem engolidos e regurgitados pelos fiéis acríticos que os aceitam como verdades inquestionáveis. Utilizou-se também de uma espécie de terrorismo moral, atribuindo o status de demônio às pessoas favoráveis ao respeito à igualdade de gênero e diversidade sexual na educação, além de intimidar profissionais de educação com notificações extrajudiciais com ameaça de processo contra quem ousasse abordar esses assuntos na sala de aula. Criou-se um movimento para "apagar" o assunto gênero do currículo escolar.

Esses elementos demostram a necessidade que a "nova direita" (CASIMIRO, 2018) tem de trazer à tona os valores do machismo, da misoginia, do racismo, do negacionismo, na heteronormatividade, para consolidar seu projeto neoliberal e se manter como classe dominante.

Dessa forma, ao se debaterem as questões referentes à concepção de corpo na BNCC, é possível perceber que as discussões acerca do corpo estão centradas na etapa da educação infantil, com bastante ênfase para o desenvolvimento corporal das crianças. Na etapa seguinte, do ensino fundamental, essas questões estão presentes com maior ênfase na disciplina de educação física e, em alguns aspectos, nas outras disciplinas como artes e ciências da natureza.

Assim, ao se olhar para a etapa da educação infantil, a BNCC apresenta cinco campos de experiência. São eles: "O eu, o outro e o nós; Corpo, gestos e movimentos; Traços, sons, cores e formas; Escuta, fala, pensamento e imaginação; e Espaços, tempos, quantidades, relações e transformações" (BRASIL, 2018, p. 25).

Nesse sentido, o corpo se apresenta como um único campo de experiência, reduzido às questões de gestos e movimentos. Entretanto, toda a experimentação que os seres humanos fazem é por meio do corpo. Pode-se com isso refletir que reduzir o corpo a gesto e movimento é uma forma de disciplinar esse corpo infantil e, segundo Louro (2018, p. 28), "Historicamente, os sujeitos tornam-se conscientes de seus corpos na medida em que há um investimento disciplinar sobre eles".

Portanto, embora a Base indique a centralidade do corpo no processo de desenvolvimento e aprendizado das crianças na educação infantil, em nenhum 
momento, ela faz referência ao desenvolvimento psicossexual; o mais próximo dessa discussão apresenta-se na página 42, ao afirmar que a criança possui curiosidade sobre seu corpo 5 (BRASIL, 2018, p. 42). Dessa forma, tratam-se os corpos infantis como algo isento de sexualidade. Reforça-se o senso comum de que na infância a sexualidade não se evidencia. Porém, segundo Vitiello e Conceição (1993, p. 49), “a sexualidade se manifesta desde o início da vida e [...] se desenvolve, acompanhando o desenvolvimento geral do indivíduo".

Por fim, um outro aspecto importante sobre o corpo, que aparece com frequência na BNCC, é o cuidado com a saúde e bem-estar. Reflexo dos modelos médicos higienistas que ditam o útil e o inútil, o normal e o patológico. Pode-se citar como exemplo, o quadro da disciplina de ciências do primeiro ano, em que o corpo e o respeito à diversidade aparecem como objeto de ensino, e as habilidades que correspondem a esse objeto de ensino são

Localizar, nomear e representar graficamente (por meio de desenhos) partes do corpo humano e explicar suas funções.

Discutir as razões pelas quais os hábitos de higiene do corpo (lavar as mãos antes de comer, escovar os dentes, limpar os olhos, o nariz e as orelhas etc.) são necessários para a manutenção da saúde.

Comparar características físicas entre os colegas, reconhecendo a diversidade e a importância da valorização, do acolhimento e do respeito às diferenças. (BRASIL, 2018, p. 333)

Sem negar a importância dessas habilidades para a vida dos(as) estudantes, mostra-se necessário relembrar que, segundo César (2009), a história da educação sexual, no Brasil, já foi permeada pela centralidade de uma moral higienista, quando o assunto era, e ainda hoje é, educação sexual. Além disso, o documento reforça o tabu de não se falar sobre as partes íntimas para as crianças, ao colocar a palavra "etc.", como se pode notar na citação acima, ao invés de nomear as genitálias, como se elas não existissem no campo da aplicação da higiene. É importante lembrar que é fundamental que as crianças saibam os nomes corretos de suas partes íntimas (assim como os diversos apelidos que culturalmente são usados) para auxiliá-las a se prevenirem de possíveis abusos bem como a denunciá-los, caso sejam vítimas de abuso sexual.

\footnotetext{
5 "Demonstram também curiosidade sobre o mundo físico (seu próprio corpo, os fenômenos atmosféricos, os animais, as plantas, as transformações da natureza, os diferentes tipos de materiais e as possibilidades de sua manipulação etc.)" (BRASIL, 2018, p. 42-43).
}

Revista Educação Online, Rio de Janeiro, n. 36, jan-abr 2021, p. 70-89 
Para seguir na análise da BNCC, referente às questões que envolvem gênero e sexualidade, é importante reafirmar a fala do ministro da Educação, ao declarar que a Base Curricular está livre da ideologia de gênero, ao atender às reivindicações de grupos ligados ao fundamentalismo religioso.

Essa negativa corresponde à concepção adotada sobre essas questões no documento, o que contraria as bandeiras de luta de diversos movimentos populares, como o feminista e o LGBTI+, entre outros, além de reforçar as concepções já existentes no senso comum.

Há também brechas que levam a refletir e a problematizar as questões de gênero, sexualidade e diversidade sexual. Observe-se a citação a seguir:

[...] cabe aos sistemas e redes de ensino, assim como às escolas, em suas respectivas esferas de autonomia e competência, incorporar aos currículos e às propostas pedagógicas a abordagem de temas contemporâneos que afetam a vida humana em escala local, regional e global, preferencialmente de forma transversal e integradora [...] bem como saúde, vida familiar e social, educação para o consumo, educação financeira e fiscal, trabalho, ciência e tecnologia e diversidade cultural. (BRASIL, 2018, p. 19-20)

Ao se ler este fragmento, levanta-se a seguinte questão: As discussões sobre corpo, gênero e sexualidade não são temas contemporâneos? Sabendo-se que existem, independentemente de se falar sobre elas, são questões que afetam vidas humanas em escala local, regional e global, e dessa maneira, deveriam fazer parte dos currículos escolares. Britzman (2018, p.140) mostra que a sexualidade tem estrita ligação com "a capacidade para a liberdade com os direitos civis e que o direito a uma informação adequada é parte daquilo que vincula a sexualidade tanto com o domínio imaginário quanto com o domínio público".

Além disso, temas como saúde, vida familiar e social, trabalho, ciências e diversidade cultural também estão presentes e se entrelaçam às questões de gênero, sexualidade e diversidade sexual.

Outra problematização necessária é sobre a relação entre a educação escolar e a educação familiar. No documento, apresenta-se a seguinte orientação:

Nesse contexto, as creches e pré-escolas, ao acolher as vivências e os conhecimentos construídos pelas crianças no ambiente da família e no contexto de sua comunidade, e articulá-los em suas propostas pedagógicas, têm o objetivo de ampliar o universo de experiências, conhecimentos e habilidades dessas crianças, diversificando e consolidando novas aprendizagens, atuando de maneira complementar à educação familiar - especialmente, quando se trata da educação dos bebês e das crianças bem pequenas, que envolve aprendizagens muito próximas aos dois contextos (familiar e

Revista Educação Online, Rio de Janeiro, n. 36, jan-abr 2021, p. 70-89 
escolar), como a socialização, a autonomia e a comunicação. (BRASIL, 2018, p.36, grifo nosso)

Por certo, a escola não deve ignorar o conhecimento que as crianças trazem de seu cotidiano familiar. Entretanto, há vários formatos de famílias que possuem valores e crenças diferentes. A questão é como a escola conseguirá corresponder a todas para, assim, complementar a educação familiar? Não deveria a escola proporcionar o conhecimento a que a criança não tem acesso fora dela, embasada nas evidências científicas atuais de cada área do conhecimento?

Seguindo na análise, a BNCC reconhece e apresenta as mudanças ocorridas no processo de transição da infância para a adolescência, mas nega as discussões de gênero. Dessa forma, o documento se torna contraditório, visto que inúmeras vezes se coloca como respeitador das diferenças. É o que se pode notar nos excertos abaixo sobre a etapa do ensino fundamental:

Além disso, e tendo por base o compromisso da escola de propiciar uma formação integral, balizada pelos direitos humanos e princípios democráticos, é preciso considerar a necessidade de desnaturalizar qualquer forma de violência nas sociedades contemporâneas, incluindo a violência simbólica de grupos sociais que impõem normas, valores e conhecimentos tidos como universais e que não estabelecem diálogo entre as diferentes culturas presentes na comunidade e na escola. (BRASIL, 2018, p.61)

É possível interpretar a citação acima, a partir do referencial existente sobre gênero, sexualidade e diversidade sexual, mas a grande questão é: Por que não tratar abertamente dessas questões? Sabe-se que a violência contra as mulheres em nossa sociedade atinge números gritantes. Segundo Lisboa (2019), em 2017, foram registrados 4,7 casos de assassinato de mulheres para cada 100 mil habitantes: a maior taxa desde 2007. Isso sem falar na violência contra a população LGBTI+.

Nesse sentido, as questões de gênero, sexualidade e diversidade sexual seguem subliminares em vários momentos do documento, passíveis da interpretação de quem fará a leitura. É na disciplina de ciências, dos anos finais do ensino fundamental, que se apresentam de forma mais direta os temas vinculados à sexualidade humana:

Nos anos finais, são abordados também temas relacionados à reprodução e à sexualidade humana, assuntos de grande interesse e relevância social nessa faixa etária, assim como são relevantes, também, o conhecimento das condições de saúde, do saneamento básico, da qualidade do ar e das condições nutricionais da população brasileira. (BRASIL, 2018 p. 327)

Revista Educação Online, Rio de Janeiro, n. 36, jan-abr 2021, p. 70-89 
Perceba-se que o documento retira o foco da discussão acerca da sexualidade ao declarar que a sexualidade humana tem a mesma relevância que o saneamento básico e outros. Não se trata de negar a importância deles em detrimento da outra, mas a forma como o documento foi redigido faz com que as questões referentes à sexualidade novamente fiquem em segundo plano.

Dessa forma, é apenas no $8^{\circ}$ ano que se irá estudar acerca da reprodução humana, conforme apresentado (Quadro 01) na BNCC:

Quadro 01 - Mecanismos reprodutivos e sexualidade na disciplina de ciências - ${ }^{\circ}$ ano.

\begin{tabular}{|c|c|c|}
\hline $\begin{array}{l}\text { UNIDADES } \\
\text { TEMÁTICAS }\end{array}$ & $\begin{array}{l}\text { OBJETOS DE } \\
\text { CONHECIMENTO }\end{array}$ & HABILIDADES \\
\hline$[\ldots]$ & {$[\ldots]$} & {$[\ldots]$} \\
\hline $\begin{array}{l}\text { Vida e evoluçăo } \\
\text { [....] }\end{array}$ & $\begin{array}{l}\text { Mecanismos } \\
\text { reprodutivos } \\
\text { Sexualidade } \\
\text { (p. } 348 \text { ) }\end{array}$ & $\begin{array}{l}\text { (EF08CI07) Comparar diferentes processos } \\
\text { reprodutivos em plantas e animais em relação aos } \\
\text { mecanismos adaptativos e evolutivos. } \\
\text { (EF08CI08) Analisar e explicar as transformações que } \\
\text { ocorrem na puberdade considerando a atuação dos } \\
\text { hormônios sexuais e do sistema nervoso. } \\
\text { (EF08CI09) Comparar o modo de ação e a eficácia dos } \\
\text { diversos métodos contraceptivos e justificar a } \\
\text { necessidade de compartilhar a responsabilidade na } \\
\text { escolha e na utilização do método mais adequado à } \\
\text { prevenção da gravidez precoce e indesejada e de } \\
\text { Doenças Sexualmente Transmissiveis (DST). } \\
\text { (EF08CI10) Identificar os principais sintomas, modos } \\
\text { de transmissão e tratamento de algumas DST (com } \\
\text { ênfase na AIDS), e discutir estratégias e métodos de } \\
\text { prevenção. } \\
\text { (EF08CI11) Selecionar argumentos que evidenciem as } \\
\text { múltiplas dimensões da sexualidade) humana } \\
\text { (biológica, sociocultural, afetiva e ética) (p. } 349 \text {, grifos } \\
\text { do autor). }\end{array}$ \\
\hline$[\ldots]$ & {$[\ldots]$} & {$[\ldots]$} \\
\hline
\end{tabular}

FONTE: Reproduzido da BNCC. (BRASIL, 2018, p. 348-349).

Nota-se, assim, o caráter biologista e higienista de tratamento do assunto, pois a ênfase está em entender o sistema reprodutor, a fim de se evitar a gravidez precoce e as Doenças Sexualmente Transmissíveis (DST). Porém, é um equívoco desconsiderar as questões de gênero, uma vez que, nas relações sexuais, se expressa o poder do sexo masculino sobre o feminino. Conforme mostra Weeks (2018, p.71), "padrões de sexualidade feminina são, inescapavelmente, um produto 
do poder dos homens para definir o que é necessário e desejável - um poder historicamente enraizado".

Também não se pode negar a importância de se discutirem as diferentes orientações sexuais, porquanto é nessa fase da vida que os adolescentes desenvolvem o interesse sexual seja pelo sexo oposto, pelo mesmo sexo, ou por ambos (ou até mesmo o desejo de não ter relações sexuais). E muitos, por certo, sofrerão vários preconceitos em função de sua orientação sexual e identidade de gênero.

Retomando a análise, destacam-se novamente as discussões sobre a disciplina de história, visto que aponta como objeto de ensino do $6^{\circ}$ ano, o "papel da mulher na Grécia e em Roma, e no período medieval” (BRASIL, 2018, p. 420) e no 9o ano: "Anarquismo e protagonismo feminino" (BRASIL, 2018, p. 428). Sem sombra de dúvidas, uma discussão importantíssima e essencial, mas que poderia se desdobrar para as demais áreas de ensino, investigando-se, por exemplo, o papel das mulheres na ciência, na literatura, no esporte e em outros campos.

A BNCC deixa nítida que sua principal preocupação é com a formação da geração que entrará no mercado de trabalho futuramente, e isso consiste em formálos não apenas intelectualmente, mas normatizando seus corpos. Com isso, é possível afirmar que essa proposta pedagógica reforça a manutenção da sociedade capitalista.

\section{Considerações finais}

As discussões apresentadas neste artigo buscaram entender como a Escola se configurou em um importante mecanismo de normatização de corpos, a fim de atender às necessidades da sociedade capitalista.

Entretanto, as discussões acerca de corpos não foram desvinculadas das questões referentes a gênero e sexualidade, uma vez que são marcas que constituem os corpos dos seres humanos e são características que demonstram relações de poder.

Percebe-se que os PCNs, embora respondam às políticas neoliberais do período, possuem uma orientação clara e definida referente às questões que envolvem gênero e sexualidade. Nesse ponto, diferem da BNCC, que negou o debate 
de gênero e sexualidade e apresentou questões referentes a gênero de maneira subliminar e concernentes à sexualidade de maneira higienista e biologista, sem levar em consideração os aspectos da afetividade e do prazer.

Dessa forma, conclui-se que a BNCC deixa brechas para se realizarem trabalhos sobre gênero, sexualidade e diversidade sexual. Todavia, o não posicionamento nítido demonstra que o documento se preocupou em atender às demandas de grupos ligados ao fundamentalismo religioso, em detrimento das pesquisas científicas voltadas ao tema.

Negar o debate não faz com que as questões deixem de existir; apenas as mantêm no senso comum - aprofundando as desigualdades e as violências -, ao não dar o tratamento mais adequado aos problemas sociais ligados à questão de gênero e sexualidade.

Fica evidente que esse projeto de educação aprofunda as desigualdades de gênero e permite a invisibilidade da violência conta as mulheres e os LGBTI+. Além disso, trata a sexualidade como um tabu, ao negar informações necessárias e fundamentais para o desenvolvimento humano saudável. Em sua grande maioria, os(as) estudantes não recebem informações adequadas de seus familiares, o que promove a facilidade do acesso à pornografia - principalmente, pelos meninos - e leva à consolidação de uma geração que tratará as mulheres como objetos, naturalizando a violência e a desigualdade de gênero.

Além disso, é comum que a escola seja responsável por boa parte de denúncias sobre abusos sexuais contra crianças e adolescentes. Portanto, ao se negar que a escola realize trabalhos referentes à sexualidade, desde a infância - certamente respeitando o desenvolvimento das crianças -, compactua-se com uma cultura de estupro e de pedofilia.

Encerra-se este trabalho, assim, reafirmando-se que educar é um ato político, e que toda proposta pedagógica se desdobra na materialidade da vida dos(as) estudantes e profissionais da educação e, consequentemente, de toda a sociedade. 


\section{Referências bibliográficas}

BRASIL. Ministério da Educação e do Desporto. Secretaria de Educação

Fundamental. Parâmetros Curriculares Nacionais: ensino fundamental. v. 10.

Brasília, 1997.

BRASIL Ministério da Educação. Em pronunciamento, ministro da Educação, Mendonça Filho destaca homologação da BNCC. Seção Rede nacional [online]. 21 dez. 2017. Disponível em <http://portal.mec.gov.br/ultimas-noticias/211218175739/58731-em-pronunciamento-ministro-da-educacao-mendonca-filhodestaca-homologacao-da-bncc>. Acesso em: 25 fev. 2020.

BRASIL Ministério da Educação. Base Nacional Comum Curricular (BNCC). $3^{a}$ versão revista. Brasília: MEC/Secretaria da Educação Básica, 2018. Disponível em: $<$ http://basenacionalcomum.mec.gov.br/images/BNCC_El_EF_110518_versaofinal_s ite.pdf>. Acesso em: $21 \mathrm{dez} .2018$.

BRÊTAS, J. R. S. Sexualidades. São Paulo: All Print, 2011.

BRITZMAN, D. Curiosidade, sexualidade e currículo. In: LOURO, Guacira Lopes (Orgs.). O corpo educado: pedagogias da sexualidade. Belo Horizonte: Autêntica, 2018. p. $105-142$

BUTLER, J. Corpos que pensam: sobre os limites discursivos do "sexo". In: LOURO, Guacira Lopes (Orgs). O corpo educado: pedagogias da sexualidade. Belo Horizonte: Autêntica, 2018. p. $191-221$.

CASIMIRO, F. H. C. A nova direita no Brasil: aparelhos de ação político-ideológica no Brasil contemporâneo. São Paulo: Expressão Popular, 2018.

CÉSAR, M. R. A. Lugar de sexo é na escola? Sexo, sexualidade e educação sexual. In: PARANÁ. Secretaria de Estado da Educação. In: PARANÁ. Secretaria de Estado da Educação. Sexualidade [on-line]. Curitiba: SEED, 2009. p. 49-58. Disponível em: $<$ http://www.educadores.diaadia.pr.gov.br/arquivos/File/cadernos_tematicos/ sexualidade.pdf>. Acesso em: 15 nov. 2019.

D'AVILA, J. B. As influências dos agentes públicos e privados no processo de elaboração da Base Nacional Comum Curricular. 2018. Dissertação (Mestrado em Educação) - Universidade Estadual do Centro-Oeste, Programa de PósGraduação Stricto Sensu em Educação do Centro de Ciências Humanas, Letras e Artes, Guarapuava, PR, 2018. Disponível em:

<http://tede.unicentro.br:8080/jspui/bitstream/jspui/1157/2/

JAQUELINE\%20BOENO\%20D\%E2\%80\%99AVILA.pdf>. Acesso em: 20 Jan. 2020.

ENGUITA, M. F. A face oculta da escola: educação e trabalho no capitalismo.

Porto Alegre: Artes Médicas, 1989.

FREITAS, L. C. A reforma empresarial da educação: nova direita, velhas ideias. São Paulo: Expressão Popular, 2018.

FURLANI, J. Encarar o desafio da educação sexual na escola. In: PARANÁ. Secretaria de Estado da Educação. Sexualidade. Curitiba: SEED, 2009. p. 37-48.

LISBOA, V. Ipea: homicídios de mulheres cresceram acima da média nacional. Entre 2012 e 2017, crimes dentro das residências cresceram 17,1\%. Agência Brasil [on- 
line], Rio de Janeiro, jun. 2019. Disponível em:

<https://agenciabrasil.ebc.com.br/geral/noticia/2019-06/ipea-homicidios-de-mulherescresceram-acima-da-media-nacional>. Acesso em: 16 mar. 2020.

LOURO, G. L. Pedagogia da sexualidade. In: (Org). O corpo educado: pedagogias da sexualidade. Belo Horizonte: Autêntica, 2018. p. 07 - 42

MACEDO, E. Base Nacional Curricular Comum: novas formas de sociabilidade produzindo sentidos para educação. E-Curriculum, São Paulo, v. 12, n. 03, p.15301555, out./dez. 2014. Disponível em: <https://revistas.pucsp.br/index.php/curriculum/article/view/21666>. Acesso em: 22 fev. 2020.

MANACORDA, M. A. História da educação: da antiguidade aos nossos dias. 13. ed. São Paulo: Cortez, 2010.

MARX, K. O capital: crítica da economia política. O processo de produção do capital. v. I, tomo I (prefácio e caps. I a XII). São Paulo: Abril, 1983.

REIS, T.; EGGERT, E. Ideologia de gênero: Uma falácia construída sobre os Planos de Educação brasileiros. Educ. Soc. [on-line], Campinas, v. 38, n. 138, p.9-26, jan./mar.2017. Disponível em:

<http://www.scielo.br/scielo.php?script=sci_abstract\&pid=S0101-

73302017000100009\&lng=en\&nrm=iso\&tlng=pt>. Acesso em: 22 fev. 2020.

SANTOS, D. B. C.; ARAUJO, D. C. Sexualidades e gêneros: questões introdutórias. In: PARANÁ. Secretaria de Estado da Educação. Sexualidade. Curitiba: SEED, 2009. p. 13-27. Disponível em:

$<$ http://www.educadores.diaadia.pr.gov.br/arquivos/File/cadernos_ tematicos/sexualidade.pdf>. Acesso em: 15 nov. 2019.

SCOTT, J. Gênero: uma categoria útil para análise histórica. New York: Columbia University Press, 1989. Disponível em:

<https://edisciplinas.usp.br/pluginfile.php/185058/mod_resource/content/2/G\%C3\%A Anero-Joan\%20Scott.pdf>. Acesso em: 26 dez. 2019.

TEIXEIRA, R. A.; PINTO, E. C. A economia política dos governos FHC, Lula e Dilma: dominância financeira, bloco no poder e desenvolvimento econômico. Econ. e Soc., Campinas, v. 21, n. especial, p. 909-941, dez. 2012. Disponível em: <http://www.scielo.br/pdf/ecos/v21nspe/v21nspea09.pdf >. Acesso em: 24 jun. 2020.

TURNER, B. S. Corpo e sociedade. Estudos em teoria social. São Paulo: Ideias e Letras, 2014.

VIANNA, C. P.; UNBEHAUM, S. Gênero e política de educação: impasses e desafios para a legislação educacional brasileira. In: SÃO PAULO: Secretaria Municipal de Educação; Coordenadoria Especial da Mulher. Educar para a igualdade: gênero e educação escolar. São Paulo: Secretaria Municipal de Educação, 2004. (Caderno da coordenadoria especial da mulher, 6).

VILELA, P. R. Mais de $70 \%$ da violência sexual contra crianças ocorre dentro de casa: campanha nacional de conscientização é realizada no mês de maio. Agência Brasil [on-line], Brasília, maio 2019. Disponível em: $<$ http://agenciabrasil.ebc.com.br/direitos-humanos/noticia/2019-05/mais-de-70-daviolencia-sexual-contra-criancas-ocorre-dentro-de>. Acesso em: 09 fev. 2020.

Revista Educação Online, Rio de Janeiro, n. 36, jan-abr 2021, p. 70-89 
VITIELLO, N.; CONCEIÇÃO, I. S. C. Manifestações da sexualidade nas diferentes fases da vida. R. bras. Sex. hum. [on-line], Rio de Janeiro, v. 4, n. 1, p.47-59, jan./jun.1993. Disponível em:

<https://www.rbsh.org.br/revista_sbrash/article/view/843/739>. Acesso em: 24 jun. 2020.

WEEKS, J. O corpo e a sexualidade. In: LOURO, Guacira Lopes (Org.). O corpo educado: pedagogias da sexualidade. Belo Horizonte: Autêntica, 2018. p.43-104

ZANATTA, L.F. et. al. Normas de gênero entre jovens "Sem Terra": evidências para a prática social de enfermagem. Rev Esc Enferm., São Paulo, v.51, e03279, p. 1-8, 2017. Disponível em http://www.scielo.br/scielo.php?script=sci_arttext\&pid=S008062342017000100480\&lng=es\&nrm=iso >. Acesso em: 10 jan. 2021 